\title{
Phosphoinositides and Membrane Targeting in Cell Polarity
}

\author{
Gerald R. Hammond and Yang Hong \\ Department of Cell Biology, University of Pittsburgh Medical School, Pittsburgh, Pennsylvania 15261 \\ Correspondence: ghammond@pitt.edu; yhong@pitt.edu
}

Selective enrichment of the polyphosphoinositides (PPIn), such as Ptdlns $(4,5) P_{2}$ and Ptdlns4P, helps to determine the identity of the plasma membrane (PM) and regulates many aspects of cell biology through a vast number of protein effectors. Polarity proteins had long been assumed to be non-PPIn-binding proteins that mainly associate with PM/cell cortex through their extensive protein-protein interaction network. However, recent studies began to reveal that several key polarity proteins electrostatically bind to PPIn through their positively charged protein domains or structures and such PPIn-binding property is essential for their direct and specific attachment to PM. Although the physical nature of the chargebased PPIn binding appears to be simple and nonspecific, it serves as an elegant mechanism that can be efficiently and specifically regulated for achieving polarized PM targeting of polarity proteins. As an unexpected consequence, subcellular localization of PPIn-binding polarity proteins are also subject to regulations by physiological conditions such as hypoxia and ischemia that acutely and reversibly depletes PPIn from PM.

$\mathrm{T}^{\mathrm{h}}$ he fundamental role of phosphoinositides (PPIn) in regulating the formation and dynamics of polarized cellular structures has been well recognized (Shewan et al. 2011; Balla 2013). During cell polarization, many studies have focused on how asymmetric distribution of PPIn in the plasma membrane (PM) plays an instrumental role in specifying membrane domains such as apical versus basolateral, and how protein effectors that bind specific PPIn such as PtdIns $(4,5) P_{2}$ or PtdIns $(3,4,5) P_{3}$ are involved in such processes (Gassama-Diagne et al. 2006; Martin-Belmonte et al. 2007; Fairn et al. 2011). However, it is also well known that PPIn, because of their negatively charged nature, can at- tract proteins carrying positive charges through nonspecific electrostatic interactions (Heo et al. 2006; Yeung et al. 2006; Hammond et al. 2012). Recent studies highlight that intracellular membranes are enriched with unique combinations of PPIn that are key to define membrane identity and determine the degree to which the surface is negatively charged (Hammond et al. 2012). PPIn such as PtdIns4P and PtdIns $(4,5) P_{2}$ are of particular importance as their unique enrichment at the inner surface of PM makes it the most negatively charged membrane surface inside the cell (Hammond et al. 2012). Although such electrostatic binding to PPIn are inherently non-structure-specific, it is nonetheless crucial

Editor: Keith E. Mostov

Additional Perspectives on Cell Polarity available at www.cshperspectives.org

Copyright (C) 2018 Cold Spring Harbor Laboratory Press; all rights reserved; doi: 10.1101/cshperspect.a027938

Cite this article as Cold Spring Harb Perspect Biol 2018;10:a027938 
to mediate the PM-specific targeting of a wide array of proteins carrying specialized domains enriched with positive charges, including MARCKS (Arbuzova et al. 2002; Morton et al. 2014), N-WASP (Papayannopoulos et al. 2005), small GTPases (Heo et al. 2006; Yeung et al. 2006), Src (McLaughlin and Aderem 1995), Ste5 (Strickfaden et al. 2007), and TRPV1 receptor regulator (Kim et al. 2008). Recent studies show that multiple polarity proteins contain positively charged domains such as polybasic domains that directly bind to PPIn (Bailey and Prehoda 2015; Dong et al. 2015). The importance of such direct PPIn binding in controlling the polarity protein subcellular localization and their functions in cell polarity has just begun to be appreciated. In this review, we will first focus on how PPIn distributions are dynamically regulated in membranes. We will then discuss how electrostatic binding to membranes serves as a pivotal mechanism regulating the PM targeting of PPIn-binding polarity proteins under both normal and stress conditions such as hypoxia. We will primarily focus on polarity proteins well characterized in Drosophila and mammalian cells for their roles in apicobasal polarization and asymmetric cell division.

\section{BIOGENESIS OF PHOSPHOINOSITIDES}

Although they are frequently relegated to the diminished status of simple, inert building blocks, lipids are in fact crucial to the biological function of membranes. Indeed, cells control lipid composition very tightly to define the functional properties of their membranes (Holthuis and Menon 2014). One family of lipids, the phosphoinositides (PPIn), are especially important in the control of membrane function. These lipids are derived from one of the major phospholipids, phosphatidylinositol (PtdIns). This lipid contains a unique polyol headgroup, which presents three hydroxylated carbons (at positions 3, 4, and 5) to the cytosol that can undergo cycles of phosphorylation and dephosphorylation by various lipid kinases and phosphatases (Fig. 1). Collectively, these enzymes can add and remove phosphatases from 3-, 4-, and 5-positions on PtdIns in all possible combinations and configurations, leading to a family of seven PPIn: three mono-, three bis-, and a single tris-phosphorylated species. Interconversion of these molecules can be extremely fast, enabling cells to rapidly modulate lipid signals, or else maintain steady-state accumulation of PPIn at

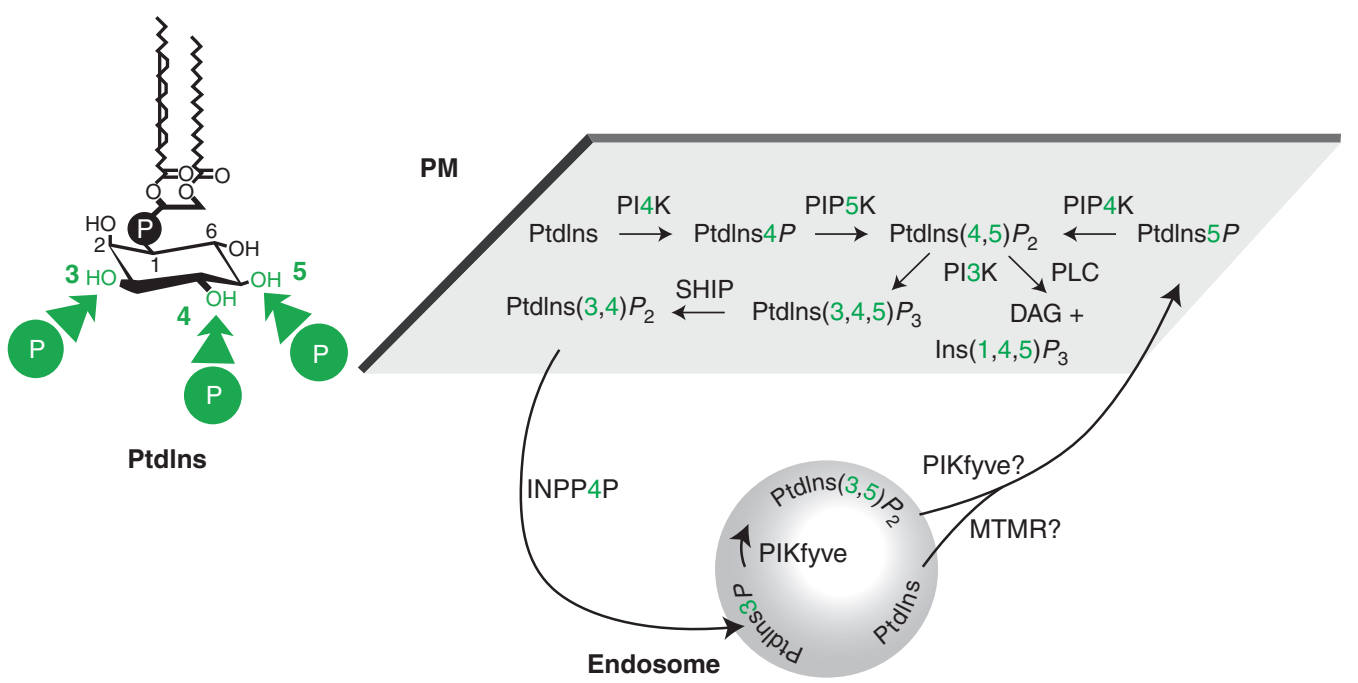

Figure 1. Generation of plasma membrane (PM) phosphoinositides. The lipid phosphatidylinositol (PtdIns) may be phosphorylated at any of three hydroxyl groups on its cytosol-exposed six-membered polyol headgroup; the major plasma membrane phosphoinositides and their synthetic pathways are indicated. 
specific compartments despite the rapid flux of lipids by vesicular and nonvesicular traffic. Once formed, the lipids can bind to hundreds of different protein partners with varying degrees of specificity to perform a dizzying array of cellular functions, from the gating of ion channels to the regulation of cell polarity and motility. This biology is vast, as are the numbers of protein effectors and enzymes that metabolize the lipids. In this review, we will restrict ourselves to the discussion of PM PPIn and their effectors that contribute to cell polarity. For a broader view of this large field, and an excellent historical perspective, we recommend the recent exhaustive review on the subject by Balla (2013).

The most abundant PPIn at the PM is PtdIns $(4,5) P_{2}$ and, in turn, the PM is where the majority of PtdIns $(4,5) P_{2}$ molecules are localized (Várnai and Balla 1998; Watt et al. 2002). Although this lipid is comparatively scarce in the cell compared with the more abundant structural phospholipids, this selective enrichment at the PM means it is relatively abundant, with a mole fraction on the cytosolic leaflet of between $1 \%$ and 5\% (James et al. 2008). It is synthesized by two separate families of kinases, each with three paralogs; the PIP5K, which phosphorylate PtdIns4P at the 5-position; and PIP4K, which phosphorylate PtdIns5P at the 4-position (Fig. 1). Because PtdIns4P is around 100-fold more abundant in cells (Sarkes and Rameh 2010), the former pathway has been assumed to be the predominant one. However, the capacity of PIP4KA to function correctly has recently been elegantly shown to depend only on its capacity to synthesize $\operatorname{PtdIns}(4,5) P_{2}$ and is unaffected by substrate preference for PtdIns5P or PtdIns4P (Bulley et al. 2015). This, coupled with the observation that most PtdIns $4 P$ is not required to synthesize PtdIns (4,5) $P_{2}$ (Hammond et al. 2012), means the question is open as to whether the PtdIns5P pathway is truly only a minor contributor to PM PtdIns $(4,5) P_{2}$ levels.

PtdIns4P is localized on several organelle membranes, including the PM, endosomes, and the Golgi (Hammond et al. 2014). Pharmacologic treatments that primarily target the PM pool indicate that $\sim 80 \%$ of the cells' PtdIns $4 P$ is in the PM (Bojjireddy et al. 2014). That being said, given PtdIns4P's enrichment on the transGolgi network (Weixel et al. 2005) and the fact that the Golgi as a whole contains less membrane surface area than the PM (Griffiths et al. 1989) means that, although there are more PtdIns4P molecules in the PM, they are probably most concentrated in the trans-Golgi network (i.e., this compartment may contain a higher mole fraction of PtdIns4P).

Synthesis of PtdIns5P is enigmatic. The best evidence to date places its synthesis at the hands of the lipid kinase PIKfyve, although it remains controversial whether synthesis occurs via direct 5-phosphoylation of PtdIns (Shisheva et al. 2015) or via a circuitous route via 5-phosphorylation of PtdIns3P followed by removal of the 3-phosphate (Fig. 1) (Zolov et al. 2012). Either way, it appears PtdIns5P synthesis occurs on endosomal membranes, yet may in fact accumulate in the plasma membrane (Roberts et al. 2005).

Once synthesized, $\operatorname{PtdIns}(4,5) P_{2}$ has a number of metabolic fates. First, it can be dephosphorylated back into PtdIns4P by the large family of inositol polyphosphate 5-phosphatase (INPP5)-domain proteins, a reaction that frequently accompanies internalization of PtdIns $(4,5) P_{2}$ molecules by endocytosis (Hakim et al. 2012). PtdIns4P is itself dephosphorylated by Sac-family phosphatases, which either occurs on nascent or early endosomes through the synaptojanin or Sac2 enzymes (Chung et al. 1997; Hsu et al. 2015; Nakatsu et al. 2015) or else by the ER-associated Sac1 lipid phosphatase; although whether this occurs through activity of Sac1 on PM PtdIns4P at ER-PM contact sites (Dickson et al. 2016) or after nonvesicular transport of PtdIns4P from the PM to the ER (Chung et al. 2015) or both has not been definitively shown.

Second, PtdIns $(4,5) P_{2}$ can be hydrolyzed by phospholipase C (PLC), which cleaves it into the second messengers diacylglycerol and Ins $P_{3}$. Depending on how robust PLC activation is, there can be no detectable change in the levels of PtdIns $(4,5) P_{2}$ after PLC activation (such as after EGF stimulation of 3T3 fibroblasts [Jackson et al. 1992]), transient reductions in the 
lipid levels that recover inside of a minute (e.g., after bombesin stimulation of the same cells [Jackson et al. 1992]), or rapid, sustained, and near complete depletion of the PM PtdIns $(4,5) P_{2}$ levels (as seen after activation of PLCcoupled muscarinic acetylcholine receptors [Willars et al. 1998]). In this latter case, PLC activity can be a means to control membrane $\operatorname{PtdIns}(4,5) P_{2}$ levels, which can be important, for example, in gating inwardly rectifying potassium channels and thus controlling electrical excitability in neurons (Suh and Hille 2002). However, it is worth emphasizing that this is by no means the normal situation for every PLC-coupled pathway.

Finally, PtdIns $(4,5) P_{2}$ can be phosphorylated by the class I PI 3-kinases at its last available 3-hydroxyl to produce $\operatorname{PtdIns}(3,4,5) P_{3}$, which like diacylglycerol and $\operatorname{Ins} P_{3}$ is an important second messenger molecule for cell signaling. It functions by recruiting and activating specific binding proteins such as Akt. PtdIns $(3,4,5) P_{3}$ generation tends to be transient (Jackson et al. 1992) or else polarized (Janetopoulos et al. 2004; Gassama-Diagne et al. 2006). This spatially or temporally restricted accumulation is controlled by phosphatases such as PTEN that remove the 3-phosphate to convert PtdIns $(3,4,5) P_{3}$ back to $\operatorname{PtdIns}(4,5) P_{2}$, or by members of the INPP5 family, namely, SHIP1 and SHIP2, that remove the 5-phosphate (Hakim et al. 2012). The resulting PtdIns $(3,4) P_{2}$ is converted to PtdIns3P on nascent endosomes by INPP4 enzymes (Shin et al. 2005a). It is important to note that, unlike PLC activity, the flux of $\operatorname{PtdIns}(4,5) P_{2}$ molecules through the PI 3-kinase pathway is comparatively low, with at most $10 \%$ of the membrane PtdIns $(4,5) P_{2}$ converted (Jackson et al. 1992). Activity of PI 3-kinases and PTEN are therefore unlikely to directly contribute to the control of PtdIns $(4,5) P_{2}$ levels.

\section{PHOSPHOINOSITIDE-DEPENDENT PM TARGETING}

There are many classes of lipid-binding domains that recognize PPIn with varying degrees of specificity and affinity. Lipid binding is often necessary but very commonly not sufficient to dictate localization of the protein (Hammond and Balla 2015); in this regard, protein - protein interactions can still play a crucial role, as we shall see. Broadly speaking, there are two classes of PPIn-binding protein (Hammond and Balla 2015): those with specific high affinity and usually $1: 1$ stoichiometric binding to a specific PPIn such as the TRAF domain (Rousseau et al. 2013), and those showing more promiscuous binding. It is to this latter category that the polybasic domains found in several polarity proteins belong.

Polybasic domains specifically bind to the PM in cells (Heo et al. 2006; Yeung et al. 2006). These proteins have long been known to bind to membranes containing anionic phospholipids through nonspecific electrostatic interactions (Wang et al. 2002), which cooperate with some hydrophobic character of the peptide such as a lipid modification or the presence of bulky hydrophobic residues such as those found in Phe and Trp. In cells, the selective targeting of the PM by polybasic domain proteins depends on their highly concentrated positive charges, because graded reduction of the net charge on the K-Ras polybasic domain from +8 to +2 broadens the protein's localization to membranes with successively lower accumulations of anionic lipids (Yeung et al. 2006).

What is the determinant on the PM that so specifically recruits these highly positively charged peptides? The anionic phospholipid phosphatidylserine (PtdSer) is most concentrated on the cytosolic leaflet of the PM, and this is an essential part of this specific membrane targeting (Yeung et al. 2008). However, the relative enrichment of PtdSer over endosomal compartments is not sufficient to explain the highly selective PM binding of the polybasic domains. In addition, it appears there is a requirement for polyanionic lipids (i.e., the PPIn) in maintaining selective binding (Heo et al. 2006; Yeung et al. 2008; Hammond et al. 2012). Because these interactions are based on nonspecific electrostatics, it is not surprising that experiments have suggested that this polyanionic lipid requirement can be met by PtdIns4P, PtdIns $(4,5) P_{2}$, or even PtdIns $(3,4,5) P_{3}$ (Heo et al. 2006; Ham- 
mond et al. 2012). However, given the higher charge density on $\operatorname{PtdIns}(4,5) P_{2}$ versus PtdIns $4 P$, and the 10- to 100-fold excess of PtdIns $(4,5) P_{2}$ over PtdIns $(3,4,5) P_{3}$, the former lipid is most likely the lipid that primarily interacts with polybasic domain proteins. In vitro, polybasic domains will specifically sequester $\operatorname{PtdIns}(4,5) P_{2}$ even in a PtdSer-rich leaflet (Gambhir et al. 2004). In fact, reversible sequestration of the lipids by polybasic domain proteins such as MARCKS has even been suggested to be a mechanism to regulate lipid levels and thus signaling (McLaughlin and Murray 2005). Collectively, it therefore seems that PtdIns $(4,5) P_{2}$ is the primary lipid involved with targeting polybasic domain proteins to the PM.

\section{PM TARGETING OF PPIn-BINDING POLARITY PROTEINS}

With few exceptions, polarity proteins typically need to specifically localize to apical or basolateral cortical/PM domains to play their regulatory functions in establishing and maintaining cell polarity (Tepass 2012; RodriguezBoulan and Macara 2014). Except for transmembrane polarity proteins such as E-cadherin and Crumbs, non-transmembrane polarity proteins were generally assumed to associate with cell cortex/PM by physically interacting with other polarity proteins and/or cortical actomyosin network (Rodriguez-Boulan and Macara 2014). For instance, protein interactions identified so far in Drosophila apical polarity complex aggregates to the transmembrane protein $\mathrm{Crb}$, which appears to act as an anchor to localize Sdt (Bachmann et al. 2001; Hong et al. 2001), Patj (Shin et al. 2005b), Par-6, and aPKC (Hurd et al. 2003), whereas E-cadherin brings the cortical localizations of $\beta$-catenin and $\mathrm{Baz}$ (Par-3) to adherens junctions (Wei et al. 2005). Interaction with the actin cytoskeleton is also considered essential to localize polarity proteins such as Lethal giant larvae (Lgl) to the cell cortex. Because of the limited resolution of optical microscopy, terms "cortical" and "membrane" were often used interchangeably in the literature describing the subcellular localization of non-transmembrane polarity proteins. Because no polarity proteins contain known PPIn-specific-binding domains such as $\mathrm{PH}$ domains, little attention was paid to their potential PPIn-binding property. Recent studies, however, began to reveal that several key polarity proteins in fact have domains that electrostatically bind to PPIn, and such direct PPIn binding can be a primary mechanism for their PM targeting.

\section{Lgl (Lethal giant larvae)}

Recent studies identified Lgl, Numb, and Miranda as the first polarity proteins that contain polybasic domains, which are essential for their PM targeting (Bailey and Prehoda 2015; Dong et al. 2015). Lgl belongs to the basolateral polarity protein group, which also contains Scrib and Dlg (Fig. 2A) (Bilder et al. 2000, 2003; Tanentzapf et al. 2000). Similar to Scrib and Dlg, Lgl plays dual roles as both a polarity protein and a tumor suppressor (Jacob et al. 1987). The precise molecular function of Lgl remains to be fully elucidated, but like many polarity proteins a key feature of Lgl is that its biological activity requires polarized localization to $\mathrm{PM} /$ cell cortex. A well-established mechanism limiting the localization of Lgl to basolateral PM is aPKC phosphorylation. In Drosophila epithelial cells, apically localized aPKC phosphorylates a highly conserved serine cluster in Lgl to prevent its localization at apical membranes (Betschinger et al. 2003; Plant et al. 2003; Hutterer et al. 2004). One early study suggests that phosphorylation of Lgl induces Lgl into a self-inhibitory conformation incapable of binding to cell cortex (Betschinger et al. 2005). However, this selfinhibiting model of $\mathrm{Lgl}$ was based on the primary sequence analysis that incorrectly predicted the carboxy-terminal half of Lgl as low complexity region. Later protein structure studies showed that Lgl and its yeast homolog Sro7 share a highly conserved structure composed of two $\beta$-propellers each containing seven WD40 blades, and the previously assumed low complexity region is actually the second $\beta$-propeller (Fig. 2B) (Hattendorf et al. 2007). It is notable though that somehow the incorrect structural model of Lgl persisted in Lgl literatures even 


\section{G.R. Hammond and Y. Hong}

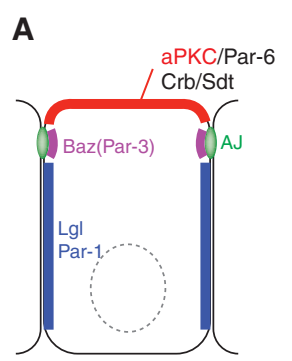

C
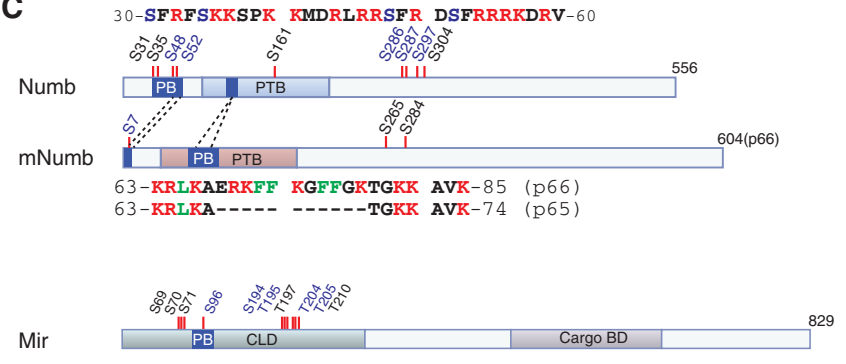

91-KEDKKSKGLR LFRTPSLPQ LRFRPTPSHT-100
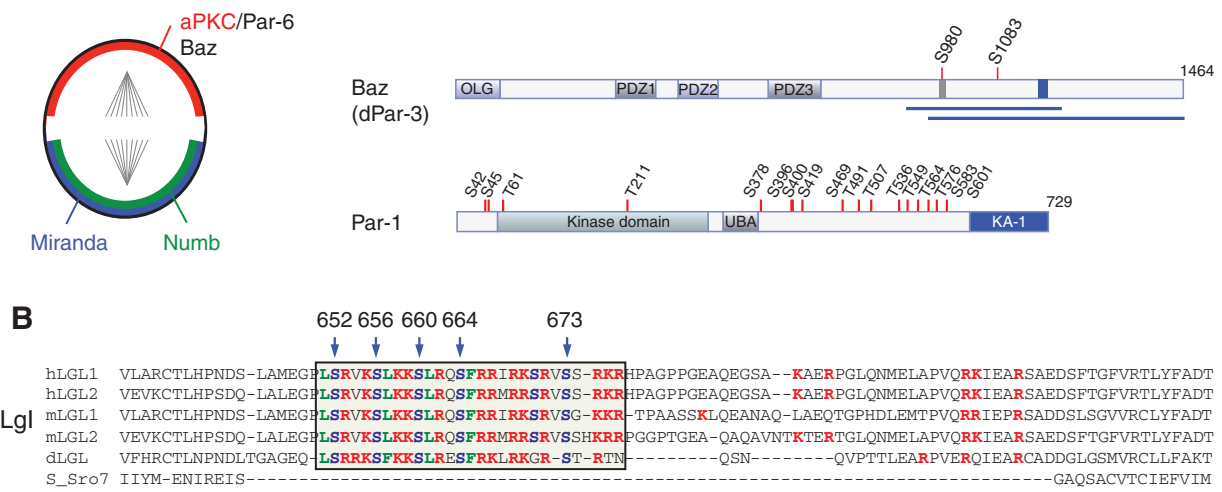

$10 \mathrm{D}$
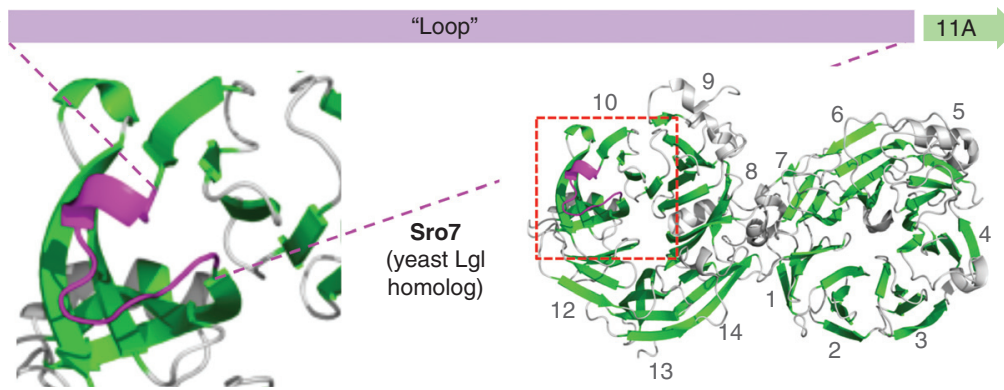

Figure 2. Polyphosphoinositides (PPIn)-binding polarity proteins. (A) Subcellular localization of key polarity proteins in epithelial cells and in dividing neuroblasts. Both cells were drawn apical side up. Only polarity proteins relevant to this review were drawn. In Drosophila epithelial cells, aPKC/Par-6 complex and Crb/Sdt(Pals1) complex localize to the apical membrane, and Bazooka (Baz) mostly localizes to apical adherens junction (AJ). Lgl and Par-1 localize to the basolateral plasma membrane (PM). In dividing neuroblasts, aPKC, Par-6, and Baz localize exclusively at the apical PM, with Numb and Miranda (Mir) at basal PM. (B) The conserved polybasic domain in Lgl. Shown at bottom right is the structure of Sro7, the yeast homolog of Lgl, which contains 14 WD40 blades ( $\beta$-sheets are in green) organized in two $\beta$-propellers (Hattendorf et al. 2007). Blades 10 and 11 are enlarged at bottom left. The loop is in magenta. Shown at the top is the alignment of the loop regions between WD40 10D and 11A $\beta$-sheets in Lgl/Sro7. Positively charged Lys and Arg residues within the loop sequences are in red and polybasic domains are boxed, Trp/Phe/Leu residues are in green and aPKC-phosphorylatable serines are in blue. Ser residues were numbered based on Drosophila $\mathrm{Lgl}(\mathrm{dLgl})$ isoform A (gi24464586). Sequence alignments are modified from Hattendorf et al. (2007). (C) PPIn-binding domains in Numb, Miranda, Baz, and Par-1. PPIn-binding domains are in blue, except that in Baz the carboxyl-terminus regions that bind PPIn are indicated by blue lines. Blue box in Baz indicates a conserved motif required for Baz PM localization in the absence of the amino terminus (Krahn et al. 2010b). Published phosphorylations sites are indicated by red vertical bars. Phosphorylation sites that regulate the polybasic domain-mediated PM targeting are in blue and those are conserved between Drosophila and mammalian Numb proteins are in bold. AJ, Adherens junction; PB, polybasic domain; PTB, phosphotyrosine-binding domain; UBA, ubiquitin-association domain; CLD, cortical localization domain; CargoBD, cargo-binding domain (Atwood and Prehoda 2009); OLG, oligomerization domain (Benton and St Johnston 2003a). 
Phosphoinositides and Membrane Targeting in Cell Polarity

well after the Sro7/Lgl structure was published (Bailey and Prehoda 2015; Bell et al. 2015; Carvalho et al. 2015).

One breakthrough on the mechanism of Lgl PM targeting comes from two recent studies. They discovered that the short $(\sim 27 \mathrm{aa})$ motif containing all the phosphorylatable serines in Lgl is in fact a typical polybasic domain (Bailey and Prehoda 2015; Dong et al. 2015). More than half the residues of the motif are either Arg or Lys, in addition to several Phe, Trp, and Leu residues that are critical for enhancing the binding of polybasic domain to the bilayer of PM (Fig. 2B) (Heo et al. 2006). In vitro Lgl polybasic domain binds directly the liposomes containing PtdIns4P and PtdIns $(4,5) P_{2}$. In vivo and in vitro data suggest that PtdIns $4 P$ and $\operatorname{PtdIns}(4,5) P_{2}$ in PM are both required for Lgl's PM localization, whereas PtdIns $(4,5) P_{2}$ plays a more significant role (Dong et al. 2015). Loss of polybasic domain completely eliminates PM localization of Lgl in cultured mammalian cells, but a Drosophila Lgl mutant with all the Arg/Lys residues mutated in the polybasic domain still showed a significantly reduced PM localization in epithelial cells in vivo (Dong et al. 2015). The residual PM localization remains sensitive to the loss of PPIn under hypoxia, suggesting a yet-to-beidentified hidden PPIn-binding domain in Lgl may mediate partial PM targeting in the absence of primary polybasic domain. Alternatively, the mutant Lgl may weakly associate with unidentified protein(s) whose PM localization also depends on PPIn. Overall, direct PPIn-binding appears to be the primary mechanism localizing Lgl to PM, in spite of the fact that Lgl also interacts with multiple target proteins such as MyoII (Dahan et al. 2012), syntaxin (Musch et al. 2002; Gangar et al. 2005), aPKC, Dlg (Zhu et al. 2014), and possibly actin cytoskeleton (Betschinger et al. 2005). Intriguingly, the polybasic domain is nearly 100\% conserved among Drosophila and mammalian Lgl proteins but is absent in yeast Sro7 (Fig. 2B), suggesting that this phosphorylatable polybasic domain (see below) is an evolutionarily acquired feature in metazoa to target Lgl to PM through direct and regulatable binding to PPIn.
Numb and Miranda

Numb and Miranda are not required for apicobasal polarization; however, they are key components in establishing the asymmetric cell division of neuroblasts in Drosophila (Fig. 2A) (Knoblich et al. 1995; Shen et al. 1997). In dividing neuroblasts, both Numb and Miranda are localized exclusively to the basal $\mathrm{PM} /$ cortex and segregate into the smaller daughter cell GMC after division. An early structure-function analysis of Drosophila Numb showed that the first 76aa of the amino terminus is both required and sufficient for Numb PM/cortical association (Knoblich et al. 1997). It is now revealed that the amino terminus of Drosophila Numb in fact contains a phosphorylatable polybasic domain that can bind PPIn (Bailey and Prehoda 2015). Furthermore, we showed that PM localization of Numb::GFP in Drosophila is sensitive to the depletion of PPIn under hypoxia (Dong et al. 2015), suggesting that binding to PPIn is likely the primary mechanism for PM targeting of Numb in Drosophila. However, interestingly the polybasic domain identified in Drosophila Numb is not conserved in vertebrates. Mammals have at least four Numb isoforms and two of them, p72 and p66, contain an 11aa insertion within in the PTB domain (Fig. 2C). The insertion creates a new and highly polybasic motif not presented in isoforms p71 and p65 or Drosophila Numb (Fig. 2C). It remains to be determined whether this alternatively spliced domain functions specifically as a PPIn-binding polybasic domain, but an early study showed that only the isoforms p72 and p66 that contain the potential polybasic motif are membrane localized and can bind PtdIns4P and PtdIns $(4,5) P_{2}$ in vitro (Dho et al. 1999). Thus, although Drosophila and mammalian Numb proteins do not share the same polybasic domain, polybasic domain-mediated PPInbinding property appears to be well conserved for their PM targeting.

The polybasic domain in Miranda is also near the amino terminus (Atwood and Prehoda 2009; Bailey and Prehoda 2015). Miranda's polybasic domain is a weaker one based on its basic hydrophobic index, but it is nonetheless 
required for Miranda localization to PM in S2 cells (Bailey and Prehoda 2015). An early study showed that the first 114aa amino-terminal sequence that contains the polybasic domain is required for the PM localization of Miranda in Drosophila (Shen et al. 1998). However, it remains to be directly tested whether this polybasic domain is required for PM targeting of Miranda in vivo.

\section{Baz/Par-3}

Bazooka (Baz) and its worm/mammalian homolog Par-3 are the first polarity protein reported to show a direct PPIn-binding property. In mammalian Par-3, the second PDZ (PDZ2) domain binds to PPIn and is required for PM localization of Par-3 in MDCK cells (Wu et al. 2007). The PDZ2 domain contains a dozen conserved Arg and Lys residues and its structure suggests that the majority of these Arg and Lys residues form a positively charged surface that may bind electrostatically to any negatively charged phospholipids (Wu et al. 2007). Next to this surface, however, lies a polar pocket that only fits well the head group of PPIn, making the PDZ2 domain selective in binding only PPIn lipids without strong structural preference for a specific PPIn. Interestingly, despite the fact that key PPIn-interacting residues are well conserved in PDZ2 domain of Baz, PDZ2 is not required for PM localization of Baz in Drosophila epithelial cells (Krahn et al. 2010b). Instead, a $\sim 300$ aa region at the carboxyl terminus is both required and sufficient for localizing Baz to PM in vivo and in $\mathrm{S}^{+} \mathrm{R}^{+}$cell. This full $300-$ 500aa carboxy-terminal region of Baz binds $\operatorname{PtdIns}(4,5) P_{2}$ and $\operatorname{PtdIns}(3,4,5) P_{3}$ liposomes in vitro (Fig. 2C) (Krahn et al. 2010b). Whereas the Baz carboxyl terminus shows stronger binding to PtdIns $(3,4,5) P_{3}$, the binding affinity measured is one or two magnitudes lower than proven PtdIns $(3,4,5) P_{3}$-specific-binding domains such as GRP1-PH (Manna et al. 2007). Such moderate binding affinity is consistent with the interactions between PPIn and Baz carboxyl terminus being charge-based with a preference for $\operatorname{Ptd} \operatorname{Ins}(3,4,5) P_{3}$ in vitro attributable to its higher negative charge. PtdIns $(4,5) P_{2}$ and
PtdIns4P are most likely responsible for Baz localization to $\mathrm{PM}$ in vivo, as $\operatorname{PtdIns}(3,4,5) P_{3}$ levels is only $\sim 1 \%$ of $\operatorname{PtdIns}(4,5) P_{2}$ in PM (Balla 2013) and depleting $\operatorname{Ptd} \operatorname{Ins}(3,4,5) P_{3}$ in Drosophila follicular cells does not affect Baz localization (Claret et al. 2014).

Neither Par-3 carboxyl terminus nor Baz PDZ2 domains has been experimentally shown for their PPIn-binding potential. However, one study showed that Par-3 carboxyl terminus is also required for its PM localization in MDCK cells (Mizuno et al. 2003). It is possible that both PDZ2 and carboxy-terminal domains can bind PPIn, but in different cell types and under different assay contexts one of them plays a more dominant role in localizing Baz/Par-3 to PM.

\section{Par-1}

Polarity protein Par-1 (or MARK in mammals) is a key Ser/Thr kinase that regulates the subcellular localization of multiple polarity proteins including Baz/Par-3 (Benton and St Johnston 2003b; Doerflinger et al. 2003). In Caenorhabditis elegans one-cell embryo and in polarized epithelial cells, Par-1 localizes to posterior or basolateral PM/cortical domain opposite to the PM domains occupied by Par-3(Baz) and aPKC (Suzuki 2015). Göransson et al. (2006) discovered that the carboxyl terminus of mammalian Par-1/MARK contains a socalled kinase-associated-1 (KA-1) domain that is required for the PM localization of Par-1 (Fig. 2C). However, it was unclear by then how KA-1, a domain only known for its potential function in kinase autoinhibition (Elbert et al. 2005), mediates the PM targeting of Par-1/MARK. The clue came years later in a survey on the yeast genome for phospholipid-binding proteins that led to the identification of a novel PPIn-binding domain in yeast septin-associated kinases (Moravcevic et al. 2010). Structure analyzes of this PPIn-binding domain revealed that it is remarkably similar to the KA-1 domain in kinases such as Par-1/MARK and MELK (Beullens et al. 2005). Although the primary sequence of KA1 domain does not resemble a typical polybasic domain, its tertiary structure revealed strong Arg/Lys-enriched surface patches. Similar to 
polybasic domain, KA-1 binds a broad array of negatively charged phospholipids including PtdSer and PPIn, with little structure specificity to a particular phospholipid (Moravcevic et al. 2010; Hammond et al. 2012). The role of KA-1 in targeting Par-1/MARK to PM in mammalian cells is now well established (Moravcevic et al. 2010), but remains to be characterized in Drosophila cells. In particular, Drosophila Par-1 has several isoforms and one of them, N1S, is missing the KA-1 domain (Shulman et al. 2000) but still shows PM localization in at least follicular epithelial cells (Doerflinger et al. 2003). Studies suggest the carboxyl terminus of N1S ("spacer" region) is both required and sufficient for Par-1N1S PM localization (Vaccari et al. 2005), but whether this region binds PPIn remains to be determined.

\section{REGULATION OF PPIn-MEDIATED TARGETING OF POLARITY PROTEINS}

At the first glance, direct binding to PM via electrostatic interactions between protein and PPIn raises the question as how such a seemingly simple and nonspecific physical interaction can be reconciled with the fact that many polarity proteins not only localize to the $\mathrm{PM}$, but are also further confined to specific PM domains. Nonetheless, several mechanisms may control the PPIn binding to achieve the polarized localization of polybasic polarity proteins such as Lgl, Numb, and Miranda (Fig. 3A).

Phosphorylation-Dependent Regulation on Electrostatic PPIn Binding

It has long been proposed that phosphorylation can function as an "electrostatic switch" to inhibit polybasic domains from binding to membrane (Mosior and McLaughlin 1991; McLaughlin and Aderem 1995; McLaughlin and Murray 2005; Mulgrew-Nesbitt et al. 2006). Phosphorylations of polybasic domain add negatively charged phosphate groups and therefore neutralize the positive charges required for polybasic domain to bind PPIn. One classic example is the scaffolding protein MARCKS whose polybasic ED domain can be phosphorylated by PKC (Hartwig et al. 1992; Arbuzova et al. 2002; Wang et al. 2002). As a polybasic protein, Lgl is remarkably similar to MARCKS as all the conserved phosphoserines identified in Lgl so far reside within the polybasic domain (Betschinger et al. 2003; Plant et al. 2003). Polybasic domains in Numb and Miranda also carry aPKC-phosphorylation sites (Bailey and Prehoda 2015; Smith et al. 2007). In either polarizing epithelial cells or dividing neuroblasts, phosphorylation by apically localized aPKC functions as an elegant mechanism to exclude Lgl, Numb, and Miranda to basolateral or basal PM (Wodarz et al. 2000; Betschinger et al. 2003; Wirtz-Peitz et al. 2008; Atwood and Prehoda 2009). This role of aPKC-phosphorylation in polarizing the PM localization of Lgl, Numb, and Miranda so far is well established, as loss of aPKC or more specifically its kinase activity (Kim et al. 2009) lead to all three proteins becoming localized around all PM domains (Wodarz et al. 2000; Betschinger et al. 2003; Wirtz-Peitz et al. 2008; Atwood and Prehoda 2009; Bell et al. 2015; Carvalho et al. 2015; Dong et al. 2015).

It is worth noting that, whereas in Lgl all the five to six aPKC-phosphorylation sites are clustered within the polybasic domain, in vitro phosphorylation assays have identified at least nine aPKC phosphorylation sites in Numb (Nishimura and Kaibuchi 2007; Smith et al. 2007) and ten in the first 300aa of Miranda (Atwood and Prehoda 2009) with the majority of them located outside the polybasic domain. The precise in vivo phosphorylation events required for aPKC to exclude Numb and Miranda remains to be fully determined. For instance, in Numb one particular phosphorylation site (S52) within the polybasic domain appears to contribute the most to apical exclusion of Numb by aPKC, but phosphorylations on four conserved sites outside the polybasic domain are required for full exclusion too (Smith et al. 2007). Similarly, eliminating the single phosphorylation site within the Miranda polybasic domain prevents aPKC from inhibiting its PM targeting, but eliminating four other phosphorylation sites $\sim 100$ aa downstream of the polybasic domain show similar effects (Atwood and 
G.R. Hammond and Y. Hong

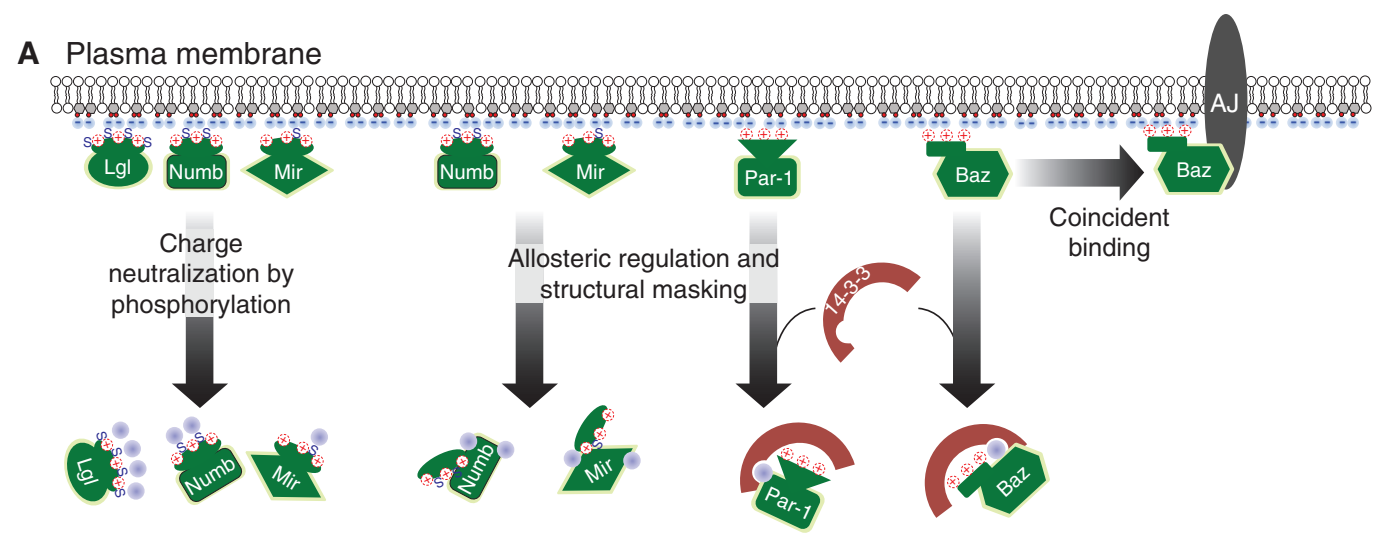

B
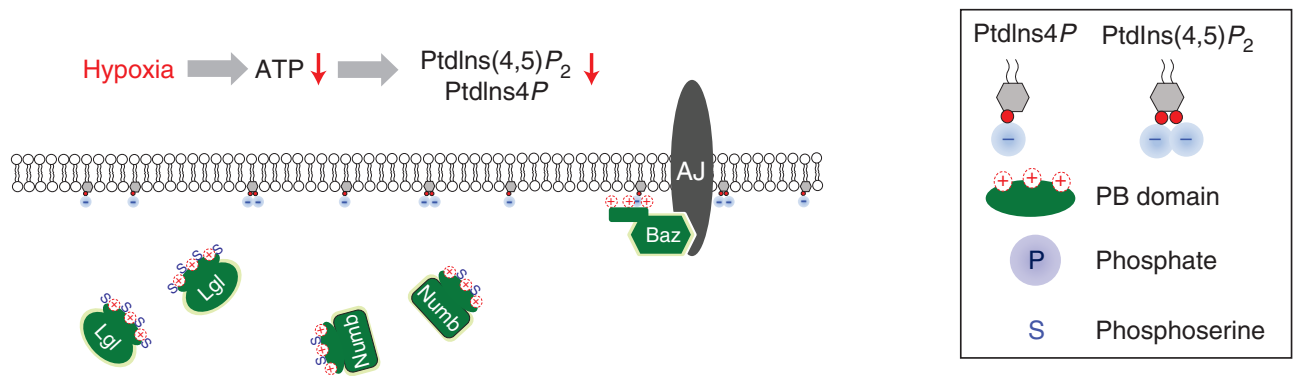

Figure 3. Regulation of polyphosphoinositides (PPIn) binding in polarity proteins. $(A)$ Three potential mechanisms that may regulate the plasma membrane (PM)-targeting of PPIn-binding polarity proteins. Events depicted in allosteric regulation and structural masking of PPIn-binding domain are hypothetical. $(B)$ Hypoxia induces ATP reduction, loss of PPIn in PM and loss of PM binding of Lgl and Numb. Lgl and Numb are the only two that are experimentally confirmed with loss of PM targeting under hypoxia. Baz remains on PM under hypoxia, likely through its interaction with protein complexes such as adherence junctions (AJs). PB, Polybasic domain.

Prehoda 2009). One way to interpret such data is that phosphorylation events outside the polybasic domain may be prerequisite for phosphorylation within the polybasic domain. However, it is also possible that in addition to neutralizing positive charges phosphorylation events may induce conformational changes that make polybasic domain less accessible to the PM, albeit experimental evidences of such mechanism remain to be shown.

Finally, excluding polybasic proteins to specific PM may involve more than passive and localized inhibition of PM binding. In Drosophila neuroblasts undergoing cell division, Miranda is at apical PM during interphase, localizes predominantly in cytosol during prophase, and only becomes concentrated to basal PM at metaphase (Erben et al. 2008). This dynamic relocalization of Miranda appears to be caused by a combination of both free diffusion and Myosin-dependent transportation of Miranda (Erben et al. 2008), and likely involves spatial-temporal regulation of aPKC activity (Wirtz-Peitz et al. 2008).

Structural Masking and Allosteric Regulation of PPIn-Binding Domain

Although neutralizing positive charges via phosphorylation on polybasic domain efficiently and specifically blocks its binding to PPIn, masking or exposing the PPIn-binding domain in a target protein by protein modifications and protein-protein interactions can also be an effective mechanism. Direct experimental evidence of such regulation of PPInbinding domain controlling the polarized PM targeting of polybasic polarity proteins are still 
lacking, but indirect evidences do suggest that polarity proteins such as Miranda, Par-1, and Baz could be the potential candidates subject to such regulations.

As mentioned earlier, aPKC-phosphorylation outside the Miranda polybasic domain could also inhibit Miranda PM localization (Atwood and Prehoda 2009), suggesting the possibility that phosphorylation-dependent protein conformation changes or protein interactions alter the accessibility of polybasic domains to bind PPIn. Par-1 has more than a dozen identified phosphorylation sites but none are in the KA-1 domain (Göransson et al. 2006). Many of these phosphorylation events induce the binding of scaffolding protein 14-3-3 (Par-5) that sequesters Par-1 to the cytoplasm (Benton et al. 2002; Benton and St Johnston 2003b; Göransson et al. 2006). Although wild-type Par-1 is often localized both on the PM and in the cytosol in cells, a Par-1 mutant with all of the phosphorylation sites eliminated appears to be exclusively on the PM in cultured cells (Göransson et al. 2006). One model consistent with such data is that binding to $14-3-3$ protein masks the KA-1 in Par- 1 and prevents it from binding the PM (Fig. 3A). $14-3-3$ can bury $>2000 \AA^{2}$ surface on a target protein (Obsil et al. 2001) and masking events by 14-3-3 have been characterized in several 14-3-3-binding targets (Bridges and Moorhead 2005; Obsil and Obsilova 2011); for instance, binding of 14-3-3 inhibits Cdc25 nuclear import by specifically occluding the nearby NLS sequence (Yang et al. 1999). Nonetheless, further experiments are required to determine whether KA-1 is similarly masked in Par-1/14-3-3 interaction. The PPIn-binding carboxy-terminal region in Baz contains the aPKC and Par-1 phosphorylation sites (Krahn et al. 2010b). Phosphorylation by Par-1 creates binding sites for 14-3-3 protein and sequesters Baz to the cytosol (Benton and St. Johnston 2003b). aPKC phosphorylation of Baz prevents its interaction with Stardust (Sdt, Pals1 in mammals), whereas eliminating the aPKCphosphorylation site results in mislocalization of $\mathrm{Baz}$ into the cytosol together with Sdt (Krahn et al. 2010a; Morais-de-Sa et al. 2010).
Again, these data are consistent with a model that binding of 14-3-3 and/or Stardust controls the PM localization of Baz by masking its PPInbinding carboxy-terminal region (Fig. 3A).

\section{Coincident Protein Interactions}

Direct PPIn binding often acts together with additional mechanisms to achieve robust and/ or polarized PM targeting (McLaughlin and Murray 2005; Hammond and Balla 2015). For instance, lipid modifications such as myristoylation enhances the PM localization of MARCKS (Arbuzova et al. 2002), and for KA1-domain-containing kinase Kcc4p, its physical interactions with septin restricts PM-bound Kcc4p to bud necks in dividing yeast (Moravcevic et al. 2010). As to the PPIn-binding polarity proteins, we are still at the beginning of discovering and characterizing their PPInbinding property and there is a lot be elucidated about how myriad protein interactions previously characterized may act coincidently with direct PM binding to achieve polarized PM localization. Baz has many confirmed interactions with apical polarity proteins such as Par-6 (Lin et al. 2000; Petronczki and Knoblich 2001; Yamanaka et al. 2001), aPKC (Izumi et al. 1998; Wodarz et al. 2000; Soriano et al. 2016), Sdt (Krahn et al. 2010a; Morais-de-Sa et al. 2010), and adherens junction complex (through $\beta$-catenin; Wei et al. 2005). Such coincident binding to apical polarity proteins may not only act to bias Baz to apical PM, but apparently also function as a redundant mechanism to retain Baz on the PM in PtdIns $(4,5) P_{2}$-deficient mutant cells (Claret et al. 2014) and in cells undergoing hypoxia-induced loss of PPIn (Dong et al. 2015). Similarly, basolateral polarity protein Dlg may specifically bind partially phosphorylated Lgl (Zhu et al. 2014; Bell et al. 2015; Carvalho et al. 2015). Such phosphorylation-dependent interaction with Dlg is not required for Lgl PM localization in vivo (Dong et al. 2015), but it may act in concert with aPKC to reinforce the basolateral PM localization of Lgl. Finally, Numb has a potential myristoylation site (Knoblich et al. 1997). Although its elimination does not appear to affect Numb PM targeting in vivo, 
it may still function to enhance the electrostatic binding of Numb to PM.

Hypoxia and ATP Depletion Regulate PPIn-Dependent PM Targeting

Whereas many studies focused on mechanisms regulating PPIn-binding domains, it has been much less appreciated that PM localization of PPIn-binding proteins can be sensitive to physiological conditions that dramatically alter PPIn levels at the PM. For instance, ATP depletion acutely and globally diminishes PPIn in PM in cultured cells (Poggioli et al. 1983). It is well established that hypoxia acutely and reversibly reduces intracellular ATP levels (DiGregorio et al. 2001), and our recent studies showed that hypoxia also induces acute and reversible depletion of membrane PtdIns $(4,5) P_{2}$ and PtdIns $(3,4,5) P_{3}$ (Dong et al. 2015). One significant consequence of such loss of PPIn is that proteins that rely on PPIn binding as their primary PMtargeting mechanism will dislocalize from the PM (Fig. 3B). Indeed, hypoxia acutely and reversibly inhibits the PM localization of Lgl and Numb in vivo. In Drosophila epithelial cells, both protein become mislocalized from PM to cytosol within an hour of acute hypoxia and relocalizes to $\mathrm{PM}$ within $\sim 10 \mathrm{~min}$ of reoxygenation (Dong et al. 2015). The time courses of Lgl and Numb PM relocalization match well with the reduction and recovery of intracellular ATP levels (DiGregorio et al. 2001) and PtdIns $(4,5) P_{2}$ and PtdIns $(3,4,5) P_{3}$ levels at PM (Dong et al. 2015) under acute hypoxia and reoxygenation. Consistent with the fact that aPKC PM localization depends on $\operatorname{PtdIns}(4,5) P_{2}$ (Claret et al. 2014), hypoxia also dislocalizes aPKC from PM (Dong et al. 2015). However, genetic reduction of PtdIns $(4,5) P_{2}$ does not acutely disrupt Baz PM localization (Claret et al. 2014) and Baz remains on PM under hypoxia (Dong et al. 2015), suggesting that in the acute loss of PPIn interactions with apical polarity complex and junctional complex likely act as a redundant mechanism to retain Baz on PM. How PM localization of Par-1 and Miranda may be affected by hypoxia and loss of PPIn have yet to be investigated.
Although many non-PPIn-binding polarity proteins and complexes such as adherens junction complex and Crb complex retain their PM localizations under hypoxia (Dong et al. 2015), the dramatic loss of PM targeting of both apical and basolateral polarity proteins such as aPKC and $\mathrm{Lgl}$ is a clear indication that apicobasal polarity in epithelial cells can be severely compromised under hypoxia. How such polarity compromise affects epithelial cells undergoing hypoxia and ischemia/reperfusion process has not been investigated. In addition, mechanisms retargeting PPIn-binding polarity proteins back to specific PM domains during reoxygenation (Dong et al. 2015) remain unknown but could be crucial to maintain/restore the cell polarity during posthypoxia recovery.

It is noteworthy that hundreds to thousands of proteins in Drosophila and mammalian genome carry potential polybasic domains (Bailey and Prehoda 2015; GR Hammond and Y Hong, unpubl.). Thus, global loss of PM PPIn attributable to hypoxia or ATP depletion does not only disrupt the PM localization of a few polarity proteins, it could have profound consequences by dislocalizing a large number of PPIn-binding proteins and their partners whose biological functions require meticulously controlled PM localization. It should be of great interest to determine how such transient but severe mislocalization of PPIn-binding proteins may contribute to the potential disruption and recovery of polarity and functions of epithelial cells during hypoxia-ischemia/ reperfusion in vivo.

\section{CONCLUDING REMARKS}

PPIn such as PtdIns $(4,5) P_{2}$ and PtdIns $4 P$ are major constituents of PM phospholipids. Although in many cells they are not necessarily asymmetrically distributed among many PM domains, as we discussed in this review, PtdIns4P and PtdIns $(4,5) P_{2}$ can play a fundamental role in cell polarity by attracting PPInbinding polarity proteins specifically to PM. The physical nature of the electrostatic interactions between charged PPIn-binding polarity proteins and PtdIns $4 P$ and $\operatorname{PtdIns}(4,5) P_{2}$ in 
PM are neither polarized nor specific to PPIn species. However, as we discussed here, several elegant mechanisms can regulate such chargebased interaction to achieve polarized and controlled PM targeting of select polarity proteins. It must be emphasized that we are still at the beginning of appreciating the fundamental role of electrostatic binding to PPIn as a means of targeting polarity proteins to the PM, and much still needs to be learned to integrate this mechanism with myriad protein-protein interactions that have so far been characterized in polarity pathways. Finally, such PPIn-bindingmediated PM targeting also brings an unexpected consequence that, for several key polarity proteins, their PM targeting becomes sensitive to the loss of PPIn induced by conditions such as hypoxia and ATP depletion, raising the question of how cell polarity may be compromised under hypoxia and ATP depletion as seen in ischemia in vivo.

\section{REFERENCES}

Arbuzova A, Schmitz AA, Vergeres G. 2002. Cross-talk unfolded: MARCKS proteins. Biochem J 362: 1-12.

Atwood SX, Prehoda KE. 2009. aPKC phosphorylates miranda to polarize fate determinants during neuroblast asymmetric cell division. Curr Biol 19: 723-729.

Bachmann A, Schneider M, Theilenberg E, Grawe F, Knust E. 2001. Drosophila Stardust is a partner of Crumbs in the control of epithelial cell polarity. Nature 414: 638-643.

Bailey MJ, Prehoda KE. 2015. Establishment of par-polarized cortical domains via phosphoregulated membrane motifs. Dev Cell 35: 199-210.

Balla T. 2013. Phosphoinositides: Tiny lipids with giant impact on cell regulation. Physiol Rev 93: 1019-1137.

Bell GP, Fletcher GC, Brain R, Thompson BJ. 2015. Aurora kinases phosphorylate Lgl to induce mitotic spindle orientation in Drosophila epithelia. Curr Biol 25: 61-68.

Benton R, St Johnston D. 2003a. A conserved oligomerization domain in Drosophila Bazooka/PAR-3 is important for apical localization and epithelial polarity. Curr Biol 13: $1330-1334$.

Benton R, St Johnston D. 2003b. Drosophila PAR-1 and 14-3-3 inhibit Bazooka/PAR-3 to establish complementary cortical domains in polarized cells. Cell 115: 691-704.

Benton R, Palacios IM, St Johnston D. 2002. Drosophila 143-3/PAR-5 is an essential mediator of PAR-1 function in axis formation. Dev Cell 3: 659-671.

Betschinger J, Mechtler K, Knoblich JA. 2003. The Par complex directs asymmetric cell division by phosphorylating the cytoskeletal protein Lgl. Nature 422: 326-330.
Betschinger J, Eisenhaber F, Knoblich JA. 2005. Phosphorylation-induced autoinhibition regulates the cytoskeletal protein Lethal (2) giant larvae. Curr Biol 15: 276-282.

Beullens M, Vancauwenbergh S, Morrice N, Derua R, Ceulemans H, Waelkens E, Bollen M. 2005. Substrate specificity and activity regulation of protein kinase MELK. J Biol Chem 280: 40003-40011.

Bilder D, Li M, Perrimon N. 2000. Cooperative regulation of cell polarity and growth by Drosophila tumor suppressors. Science 289: 113-116.

Bilder D, Schober M, Perrimon N. 2003. Integrated activity of PDZ protein complexes regulates epithelial polarity. Nat Cell Biol 5: 53-58.

Bojjireddy N, Botyanszki J, Hammond GRV, Creech D, Peterson R, Kemp DC, Snead M, Brown R, Morrison A, Wilson S, et al. 2014. Pharmacological and genetic targeting of the PI4KA enzyme reveals its important role in maintaining plasma membrane phosphatidylinositol 4phosphate and phosphatidylinositol 4,5-bisphosphate levels. J Biol Chem 289: 6120-6132.

Bridges D, Moorhead GBG. 2005. 14-3-3 proteins: A number of functions for a numbered protein. Sci STKE 2005: re10-re10.

Bulley SJ, Clarke JH, Droubi A, Giudici ML, Irvine RF. 2015. Exploring phosphatidylinositol 5-phosphate 4-kinase function. Adv Biol Regul 57: 193-202.

Carvalho CA, Moreira S, Ventura G, Sunkel CE, Morais-deSá E. 2015. Aurora A triggers Lgl cortical release during symmetric division to control planar spindle orientation. Curr Biol 25: 53-60.

Chung JK, Sekiya F, Kang HS, Lee C, Han JS, Kim SR, Bae YS, Morris AJ, Rhee SG. 1997. Synaptojanin inhibition of phospholipase $\mathrm{D}$ activity by hydrolysis of phosphatidylinositol 4,5-bisphosphate. J Biol Chem 272: $15980-$ 15985.

Chung J, Torta F, Masai K, Lucast L, Czapla H, Tanner LB, Narayanaswamy P, Wenk MR, Nakatsu F, DeCamilli P. 2015. Intracellular transport. PI4P/phosphatidylserine countertransport at ORP5- and ORP8-mediated ERplasma membrane contacts. Science 349: 428-432.

Claret S, Jouette J, Benoit B, Legent K, Guichet A. 2014. $\mathrm{PI}(4,5) \mathrm{P}_{2}$ produced by the PI4P5K SKTL controls apical size by tethering PAR-3 in Drosophila epithelial cells. Curr Biol 24: 1071-1079.

Dahan I, Yearim A, Touboul Y, Ravid S. 2012. The tumor suppressor Lgl1 regulates NMII-A cellular distribution and focal adhesion morphology to optimize cell migration. Mol Biol Cell 23: 591-601.

Dho SE, French MB, Woods SA, McGlade CJ. 1999. Characterization of four mammalian Numb protein isoforms: Identification of cytoplasmic and membrane-associated variants of the phosphotyrosine binding domain. J Biol Chem 274: 33097-33104.

Dickson EJ, Jensen JB, Vivas O, Kruse M, Traynor-Kaplan AE, Hille B. 2016. Dynamic formation of ER-PM junctions presents a lipid phosphatase to regulate phosphoinositides. J Cell Biol 213: 33-48.

DiGregorio PJ, Ubersax JA, O'Farrell PH. 2001. Hypoxia and nitric oxide induce a rapid, reversible cell cycle arrest of the Drosophila syncytial divisions. J Biol Chem 276: 1930-1937. 
G.R. Hammond and Y. Hong

Doerflinger H, Benton R, Shulman JM, St Johnston D. 2003. The role of PAR-1 in regulating the polarised microtubule cytoskeleton in the Drosophila follicular epithelium. Development 130: 3965-3975.

Dong W, Zhang X, Liu W, Chen Yj, Huang J, Austin E, Celotto AM, Jiang WZ, Palladino MJ, Jiang Y, et al. 2015. A conserved polybasic domain mediates plasma membrane targeting of $\mathrm{Lgl}$ and its regulation by hypoxia. J Cell Biol 211: 273-286,

Elbert M, Rossi G, Brennwald P. 2005. The yeast Par-1 homologs Kin1 and Kin2 show genetic and physical interactions with components of the exocytic machinery. Mol Biol Cell 16: 532-549.

Erben V, Waldhuber M, Langer D, Fetka I, Jansen RP, Petritsch C. 2008. Asymmetric localization of the adaptor protein Miranda in neuroblasts is achieved by diffusion and sequential interaction of Myosin II and VI. J Cell Sci 121: $1403-1414$.

Fairn GD, Hermansson M, Somerharju P, Grinstein S. 2011 Phosphatidylserine is polarized and required for proper Cdc42 localization and for development of cell polarity. Nat Cell Biol 13: 1424-1430.

Gambhir A, Hangyás-Mihályné G, Zaitseva I, Cafiso DS, Wang J, Murray D, Pentyala SN, Smith SO, McLaughlin S. 2004. Electrostatic sequestration of PIP2 on phospholipid membranes by basic/aromatic regions of proteins. Biophys J 86: 2188-2207.

Gangar A, Rossi G, Andreeva A, Hales R, Brennwald P. 2005. Structurally conserved interaction of $\operatorname{Lgl}$ family with SNAREs is critical to their cellular function. Curr Biol 15: 1136-1142.

Gassama-Diagne A, Yu W, ter Beest M, Martin-Belmonte F, Kierbel A, Engel J, Mostov K. 2006. Phosphatidylinositol3,4,5-trisphosphate regulates the formation of the basolateral plasma membrane in epithelial cells. Nat Cell Biol 8: $963-970$.

Göransson O, Deak M, Wullschleger S, Morrice NA, Prescott AR, Alessi DR. 2006. Regulation of the polarity kinases PAR-1/MARK by 14-3-3 interaction and phosphorylation. J Cell Sci 119: 4059-4070.

Griffiths G, Back R, Marsh M. 1989. A quantitative analysis of the endocytic pathway in baby hamster kidney cells. J Cell Biol 109: 2703-2720.

Hakim S, Bertucci MC, Conduit SE, Vuong DL, Mitchell C. 2012. Inositol polyphosphate phosphatases in human disease. Curr Topics Microbiol Immunol 362: 247-314.

Hammond GRV, Balla T. 2015. Polyphosphoinositide binding domains: Key to inositol lipid biology. Biochim Biophys Acta 1851: 746-758.

Hammond GRV, Fischer MJ, Anderson KE, Holdich J, Koteci A, Balla T, Irvine RF. 2012. PI4P and $\mathrm{PI}(4,5) P_{2}$ are essential but independent lipid determinants of membrane identity. Science 337: 727-730.

Hammond GRV, Machner MP, Balla T. 2014. A novel probe for phosphatidylinositol 4-phosphate reveals multiple pools beyond the Golgi. J Cell Biol 205: 113-126.

Hartwig JH, Thelen M, Resen A, Janmey PA, Nairn AC, Aderem A. 1992. MARCKS is an actin filament crosslinking protein regulated by protein kinase $\mathrm{C}$ and calciumcalmodulin. Nature 356: 618-622.
Hattendorf DA, Andreeva A, Gangar A, Brennwald PJ, Weis WI. 2007. Structure of the yeast polarity protein Sro7 reveals a SNARE regulatory mechanism. Nature 446: 567-571.

Heo WD, Inoue T, Park WS, Kim ML, Park BO, Wandless TJ, Meyer T. 2006. $\mathrm{PI}(3,4,5) P_{3}$ and $\mathrm{PI}(4,5) P_{2}$ lipids target proteins with polybasic clusters to the plasma membrane. Science 314: $1458-1461$.

Holthuis J, Menon AK. 2014. Lipid landscapes and pipelines in membrane homeostasis. Nature 510: 48-57.

Hong Y, Stronach B, Perrimon N, Jan LY, Jan YN. 2001. Drosophila Stardust interacts with Crumbs to control polarity of epithelia but not neuroblasts. Nature 414: 634638.

Hsu F, Hu F, Mao Y, Mao Y. 2015. Spatiotemporal control of phosphatidylinositol 4-phosphate by Sac2 regulates endocytic recycling. J Cell Biol 209: 97-110.

Hurd TW, Gao L, Roh MH, Macara IG, Margolis B. 2003. Direct interaction of two polarity complexes implicated in epithelial tight junction assembly. Nat Cell Biol 5: 137142.

Hutterer A, Betschinger J, Petronczki M, Knoblich JA. 2004. Sequential roles of Cdc42, Par-6, aPKC, and Lgl in the establishment of epithelial polarity during Drosophila embryogenesis. Dev Cell 6: 845-854.

Izumi Y, Hirose T, Tamai Y, Hirai S, Nagashima Y, Fujimoto T, Tabuse Y, Kemphues KJ, Ohno S. 1998. An atypical PKC directly associates and colocalizes at the epithelial tight junction with ASIP, a mammalian homologue of Caenorhabditis elegans polarity protein PAR-3. J Cell Biol 143: 95-106.

Jackson TR, Stephens L, Hawkins PT. 1992. Receptor specificity of growth factor-stimulated synthesis of 3-phosphorylated inositol lipids in Swiss 3T3 cells. J Biol Chem 267: 16627-16636.

Jacob L, Opper M, Metzroth B, Phannavong B, Mechler BM. 1987. Structure of the $l(2) g l$ gene of Drosophila and delimitation of its tumor suppressor domain. Cell 50: 215 225.

James DJ, Khodthong C, Kowalchyk JA, Martin TFJ. 2008. Phosphatidylinositol 4,5-bisphosphate regulates SNARE-dependent membrane fusion. J Cell Biol 182: 355-366.

Janetopoulos C, Ma L, Devreotes PN, Iglesias PA. 2004. Chemoattractant-induced phosphatidylinositol 3,4,5trisphosphate accumulation is spatially amplified and adapts, independent of the actin cytoskeleton. Proc Natl Acad Sci 101: 8951-8956.

Kim AY, Tang Z, Liu Q, Patel KN, Maag D, Geng Y, Dong X. 2008. Pirt, a phosphoinositide-binding protein, functions as a regulatory subunit of TRPV1. Cell 133: 475485.

Kim S, Gailite I, Moussian B, Luschnig S, Goette M, Fricke K, Honemann-Capito M, Grubmuller H, Wodarz A. 2009. Kinase-activity-independent functions of atypical protein kinase C in Drosophila. J Cell Sci 122: 3759-3771.

Knoblich JA, Jan LY, Nung JY. 1995. Asymmetric segregation of Numb and Prospero during cell division. Nature 377: 624-627.

Knoblich JA, Jan LY, Jan YN. 1997. The N terminus of the Drosophila Numb protein directs membrane association 
and actin-dependent asymmetric localization. Proc Natl Acad Sci 94: 13005-13010.

Krahn MP, Buckers J, Kastrup L, Wodarz A. 2010a. Formation of a Bazooka-Stardust complex is essential for plasma membrane polarity in epithelia. J Cell Biol 190: 751760.

Krahn MP, Klopfenstein DR, Fischer N, Wodarz A. 2010b. Membrane targeting of Bazooka/PAR-3 is mediated by direct binding to phosphoinositide lipids. Curr Biol 20: 636-642.

Lin D, Edwards AS, Fawcett JP, Mbamalu G, Scott JD, Pawson T. 2000. A mammalian PAR-3-PAR-6 complex implicated in Cdc42/Racl and aPKC signalling and cell polarity. Nat Cell Biol 2: 540-547.

Manna D, Albanese A, Park WS, Cho W. 2007. Mechanistic basis of differential cellular responses of phosphatidylinositol 3,4-bisphosphate- and phosphatidylinositol 3,4,5-trisphosphate-binding Pleckstrin homology domains. J Biol Chem 282: 32093-32105.

Martin-Belmonte F, Gassama A, Datta A, Yu W, Rescher U, Gerke V, Mostov K. 2007. PTEN-mediated apical segregation of phosphoinositides controls epithelial morphogenesis through Cdc42. Cell 128: 383-397.

McLaughlin S, Aderem A. 1995. The myristoyl-electrostatic switch: A modulator of reversible protein-membrane interactions. Trends Biochem Sci 20: 272-276.

McLaughlin S, Murray D. 2005. Plasma membrane phosphoinositide organization by protein electrostatics. $\mathrm{Na}$ ture 438: 605-611.

Mizuno K, Suzuki A, Hirose T, Kitamura K, Kutsuzawa K, Futaki M, Amano Y, Ohno S. 2003. Self-association of PAR-3-mediated by the conserved N-terminal domain contributes to the development of epithelial tight junctions. J Biol Chem 278: 31240-31250.

Morais-de-Sa E, Mirouse V, St Johnston D. 2010. aPKC phosphorylation of Bazooka defines the apical/lateral border in Drosophila epithelial cells. Cell 141: 509-523.

Moravcevic K, Mendrola JM, Schmitz KR, Wang YH, Slochower D, Janmey PA, Lemmon MA. 2010. Kinase associated-1 domains drive MARK/PAR1 kinases to membrane targets by binding acidic phospholipids. Cell 143: 966-977.

Morton LA, Tamura R, de Jesus AJ, Espinoza A, Yin H. 2014 Biophysical investigations with MARCKS-ED: Dissecting the molecular mechanism of its curvature sensing behaviors. Biochim Biophys Acta 1838: 3137-3144.

Mosior M, McLaughlin S. 1991. Peptides that mimic the pseudosubstrate region of protein kinase $\mathrm{C}$ bind to acidic lipids in membranes. Biophys J 60: 149-159.

Mulgrew-Nesbitt A, Diraviyam K, Wang J, Singh S, Murray P, Li Z, Rogers L, Mirkovic N, Murray D. 2006. The role of electrostatics in protein-membrane interactions. Biochim Biophys Acta 1761: 812-826.

Musch A, Cohen D, Yeaman C, Nelson WJ, Rodriguez-Boulan E, Brennwald PJ. 2002. Mammalian homolog of Drosophila tumor suppressor lethal (2) giant larvae interacts with basolateral exocytic machinery in Madin-Darby canine kidney cells. Mol Biol Cell 13: 158-168.

Nakatsu F, Messa M, Nandez R, Czapla H, Zou Y, Strittmatter SM, DeCamilli P. 2015. Sac2/INPP5F is an inositol 4- phosphatase that functions in the endocytic pathway. $J$ Cell Biol 209: 85-95.

Nishimura T, Kaibuchi K. 2007. Numb controls integrin endocytosis for directional cell migration with aPKC and PAR-3. Dev Cell 13: 15-28.

Obsil T, Obsilova V. 2011. Structural basis of 14-3-3 protein functions. Semin Cell Dev Biol 22: 663-672.

Obsil T, Ghirlando R, Klein DC, Ganguly S, Dyda F. 2001. Crystal structure of the 14-3-3५:serotonin $N$-acetyltransferase complex: A role for scaffolding in enzyme regulation. Cell 105: 257-267.

Papayannopoulos V, Co C, Prehoda KE, Snapper S, Taunton J, Lim WA. 2005. A polybasic motif allows N-WASP to act as a sensor of PIP2 density. Mol Cell 17: 181-191.

Petronczki M, Knoblich JA. 2001. DmPAR-6 directs epithelial polarity and asymmetric cell division of neuroblasts in Drosophila. Nat Cell Biol 3: 43-49.

Plant PJ, Fawcett JP, Lin DC, Holdorf AD, Binns K, Kulkarni S, Pawson T. 2003. A polarity complex of mPar-6 and atypical PKC binds, phosphorylates and regulates mammalian Lgl. Nat Cell Biol 5: 301-308.

Poggioli J, Weiss SJ, McKinney JS, Putney JW. 1983. Effects of antimycin A on receptor-activated calcium mobilization and phosphoinositide metabolism in rat parotid gland. Mol Pharmacol 23: 71-77.

Roberts HF, Clarke JH, Letcher AJ, Irvine RF, Hinchliffe KA. 2005. Effects of lipid kinase expression and cellular stimuli on phosphatidylinositol 5-phosphate levels in mammalian cell lines. FEBS Lett 579: 2868-2872.

Rodriguez-Boulan E, Macara IG. 2014. Organization and execution of the epithelial polarity programme. Nat Rev Mol Cell Biol 15: 225-242.

Rousseau A, McEwen AG, Poussin-Courmontagne P, Rognan D, Nominé Y, Rio MC, Tomasetto C, Alpy F. 2013. TRAF4 is a novel phosphoinositide-binding protein modulating tight junctions and favoring cell migration. PLoS Biol 11: e1001726.

Sarkes D, Rameh LE. 2010. A novel HPLC-based approach makes possible the spatial characterization of cellular PtdIns5P and other phosphoinositides. Biochem J 428: 375-384.

Shen CP, Jan LY, Jan YN. 1997. Miranda is required for the asymmetric localization of Prospero during mitosis in Drosophila. Cell 90: 449-458.

Shen CP, Knoblich JA, Chan YM, Jiang MM, Jan LY, Jan YN. 1998. Miranda as a multidomain adapter linking apically localized Inscuteable and basally localized Staufen and Prospero during asymmetric cell division in Drosophila. Genes Dev 12: 1837-1846.

Shewan A, Eastburn DJ, Mostov K. 2011. Phosphoinositides in cell architecture. Cold Spring Harb Perspect Biol 3: a004796.

Shin HW, DeCamilli P, Hayashi M, Christoforidis S, LacasGervais S, Hoepfner S, Wenk MR, Modregger J, Uttenweiler-Joseph S, Wilm M, et al. 2005a. An enzymatic cascade of Rab5 effectors regulates phosphoinositide turnover in the endocytic pathway. J Cell Biol 170: 607618.

Shin K, Straight S, Margolis B. 2005b. PATJ regulates tight junction formation and polarity in mammalian epithelial cells. J Cell Biol 168: 705-711. 
G.R. Hammond and Y. Hong

Shisheva A, Sbrissa D, Ikonomov O. 2015. Plentiful PtdIns5P from scanty PtdIns $(3,5) P_{2}$ or from ample PtdIns? PIKfyve-dependent models: Evidence and speculation (response to: DOI 10.1002/bies.201300012). BioEssays 37: 267-277.

Shulman JM, Benton R, St Johnston D. 2000. The Drosophila homolog of C. elegans PAR-1 organizes the oocyte cytoskeleton and directs oskar mRNA localization to the posterior pole. Cell 101: 377-388.

Smith CA, Lau KM, Rahmani Z, Dho SE, Brothers G, She YM, Berry DM, Bonneil E, Thibault P, Schweisguth F, et al. 2007. aPKC-mediated phosphorylation regulates asymmetric membrane localization of the cell fate determinant Numb. $E M B O J$ 26: 468-480.

Soriano EV, Ivanova ME, Fletcher G, Riou P, Knowles PP, Barnouin K, Purkiss A, Kostelecky B, Saiu P, Linch M, et al. 2016. aPKC Inhibition by Par3 CR3 flanking regions controls substrate access and underpins apical-junctional polarization. Dev Cell 38: 384-398.

Strickfaden SC, Winters MJ, Ben-Ari G, Lamson RE, Tyers M, Pryciak PM. 2007. A mechanism for cell-cycle regulation of MAP kinase signaling in a yeast differentiation pathway. Cell 128: 519-531.

Suh BC, Hille B. 2002. Recovery from muscarinic modulation of $\mathrm{M}$ current channels requires phosphatidylinositol 4,5-bisphosphate synthesis. Neuron 35: 507-520.

Suzuki A. 2015. PAR-1 kinase and cell polarity. In Cell polarity 1: Biological role basic mechanisms (ed. Ebnet K), pp. 25-50. Springer, New York.

Tanentzapf G, Smith C, McGlade J, Tepass U. 2000. Apical, lateral, and basal polarization cues contribute to the development of the follicular epithelium during Drosophila oogenesis. J Cell Biol 151: 891-904.

Tepass U. 2012. The apical polarity protein network in Drosophila epithelial cells: Regulation of polarity, junctions, morphogenesis, cell growth, and survival. Апnи Rev Cell Dev Biol 28.

Vaccari T, Rabouille C, Ephrussi A. 2005. The Drosophila PAR-1 spacer domain is required for lateral membrane association and for polarization of follicular epithelial cells. Curr Biol 15: 255-261.

Várnai P, Balla T. 1998. Visualization of phosphoinositides that bind pleckstrin homology domains: Calcium- and agonist-induced dynamic changes and relationship to myo- $\left[{ }^{3} \mathrm{H}\right]$ inositol-labeled phosphoinositide pools. J Cell Biol 143: 501-510.

Wang J, Gambhir A, Hangyás-Mihályné G, Murray D, Golebiewska U, McLaughlin S. 2002. Lateral sequestration of phosphatidylinositol 4,5-bisphosphate by the basic effector domain of myristoylated alanine-rich $\mathrm{C}$ kinase substrate is due to nonspecific electrostatic interactions. J Biol Chem 277: 34401-34412.
Watt SA, Kular G, Fleming IN, Downes CP, Lucocq J. 2002. Subcellular localization of phosphatidylinositol 4,5-bisphosphate using the pleckstrin homology domain of phospholipase C $\delta_{1}$. Biochem J 363: 657-666.

Wei SY, Escudero LM, Yu F, Chang LH, Chen LY, Ho YH, Lin CM, Chou CS, Chia W, Modolell J, et al. 2005. Echinoid is a component of adherens junctions that cooperates with DE-cadherin to mediate cell adhesion. Dev Cell 8: 493504.

Weixel KM, Blumental-Perry A, Watkins SC, Aridor M, Weisz OA. 2005. Distinct Golgi populations of phosphatidylinositol 4-phosphate regulated by phosphatidylinositol 4-kinases. J Biol Chem 280: 10501-10508.

Willars GB, Nahorski SR, Challiss RA. 1998. Differential regulation of muscarinic acetylcholine receptor-sensitive polyphosphoinositide pools and consequences for signaling in human neuroblastoma cells. J Biol Chem 273: 5037-5046.

Wirtz-Peitz F, Nishimura T, Knoblich JA. 2008. Linking cell cycle to asymmetric division: Aurora-A phosphorylates the par complex to regulate Numb localization. Cell 135: $161-173$.

Wodarz A, Ramrath A, Grimm A, Knust E. 2000. Drosophila atypical protein kinase $\mathrm{C}$ associates with Bazooka and controls polarity of epithelia and neuroblasts. J Cell Biol 150: $1361-1374$.

Wu H, Feng W, Chen J, Chan LN, Huang S, Zhang M. 2007. PDZ domains of Par-3 as potential phosphoinositide signaling integrators. Mol Cell 28: 886-898.

Yamanaka T, Horikoshi Y, Suzuki A, Sugiyama Y, Kitamura K, Maniwa R, Nagai Y, Yamashita A, Hirose T, Ishikawa H, et al. 2001. PAR-6 regulates aPKC activity in a novel way and mediates cell-cell contact-induced formation of the epithelial junctional complex. Genes Cells 6: 721-731.

Yang J, Winkler K, Yoshida M, Kornbluth S. 1999. Maintenance of $\mathrm{G}_{2}$ arrest in the Xenopus oocyte: A role for 14-33 -mediated inhibition of Cdc25 nuclear import. EMBO J 18: 2174-2183.

Yeung T, Terebiznik M, Yu L, Silvius J, Abidi WM, Philips M, Levine T, Kapus A, Grinstein S. 2006. Receptor activation alters inner surface potential during phagocytosis. Science 313: 347-351.

Yeung T, Gilbert GE, Shi J, Silvius J, Kapus A, Grinstein S. 2008. Membrane phosphatidylserine regulates surface charge and protein localization. Science 319: 210-213.

Zhu J, Shang Y, Wan Q, Xia Y, Chen J, Du Q, Zhang M. 2014. Phosphorylation-dependent interaction between tumor suppressors Dlg and Lgl. Cell Res 24: 451-463.

Zolov SN, Bridges D, Zhang Y, Lee WW, Riehle E, Verma R, Lenk GM, Converso-Baran K, Weide T, Albin RL, et al. 2012. In vivo, Pikfyve generates $\mathrm{PI}(3,5) P_{2}$, which serves as both a signaling lipid and the major precursor for PI5P. Proc Natl Acad Sci 109: 17472-17477. 


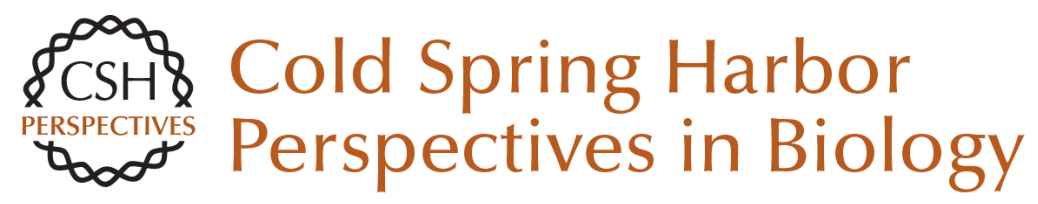

\section{Phosphoinositides and Membrane Targeting in Cell Polarity}

Gerald R. Hammond and Yang Hong

Cold Spring Harb Perspect Biol 2018; doi: 10.1101/cshperspect.a027938 originally published online March 6, 2017

\section{Subject Collection Cell Polarity}

Regulation of Cell Polarity by Exocyst-Mediated Trafficking Noemi Polgar and Ben Fogelgren

Phosphoinositides and Membrane Targeting in Cell Polarity Gerald R. Hammond and Yang Hong

Trafficking lon Transporters to the Apical Membrane of Polarized Intestinal Enterocytes Amy Christine Engevik and James R. Goldenring

Signaling Networks in Epithelial Tube Formation Ilenia Bernascone, Mariam Hachimi and Fernando Martin-Belmonte

Making Heads or Tails of It: Cell-Cell Adhesion in Cellular and Supracellular Polarity in Collective Migration Jan-Hendrik Venhuizen and Mirjam M. Zegers

Laminins in Epithelial Cell Polarization: Old Questions in Search of New Answers Karl S. Matlin, Satu-Marja Myllymäki and Aki Manninen

Epithelial Morphogenesis during Liver Development

Naoki Tanimizu and Toshihiro Mitaka

Targeting the Mucosal Barrier: How Pathogens Modulate the Cellular Polarity Network Travis R. Ruch and Joanne N. Engel
The Crumbs3 Polarity Protein Ben Margolis

Microtubule Motors in Establishment of Epithelial Cell Polarity Geri Kreitzer and Monn Monn Myat

Role of Polarity Proteins in the Generation and Organization of Apical Surface Protrusions Gerard Apodaca

Polarized Exocytosis Jingwen Zeng, Shanshan Feng, Bin Wu, et al.

Regulation of Transporters and Channels by Membrane-Trafficking Complexes in Epithelial Cells

Curtis T. Okamoto

Membrane Transport across Polarized Epithelia Maria Daniela Garcia-Castillo, Daniel J.-F. Chinnapen and Wayne I. Lencer

Mechanisms of Cell Polarity-Controlled Epithelial Homeostasis and Immunity in the Intestine Leon J. Klunder, Klaas Nico Faber, Gerard Dijkstra, et al.

The Biology of Ciliary Dynamics Kuo-Shun Hsu, Jen-Zen Chuang and Ching-Hwa Sung

For additional articles in this collection, see http://cshperspectives.cshlp.org/cgi/collection/

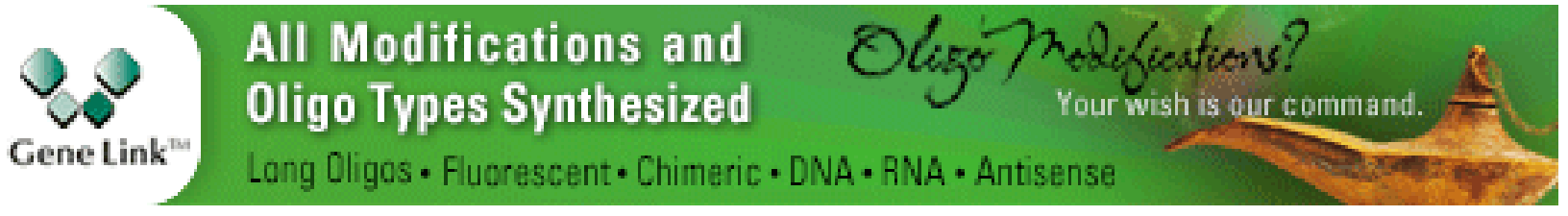

